\title{
Pengaruh Kepemimpinan Transformasional, Budaya Organisasi, dan Orientasi Strategis Terhadap Kinerja Organisasi Melalui Peran Mediasi Knowledge Management (Studi pada PDAM di Nusa Tenggara Barat)
}

\author{
Oleh \\ Dr. Hermanto, MBA*
}

\begin{abstract}
Abstrak
Penelitian ini bertujuan untuk menguji dan menjelaskan dampak langsung kepemimpinan transformasional, budaya organisasi, dan orientasi strategis terhadap kinerja organisasi, serta dampak tidak langsung dari variabel tersebut melalui peran mediasi knowledge management. Melalui pendekatan kuantitatif, data dikumpulkan menggunakan metode survei dan dianalisis menggunakan GESCA. Semua perusahaan daerah air minum (PDAM) di Nusa Tenggara Barat terlibat sebagai unit analisis penelitian ini dimana 70 manajer di tingkat atas dan menengah diperlakukan sebagai responden penelitian. Penelitian menunjukkan bahwa ada pengaruh langsung positif dan signifikan dari knowledge management terhadap kinerja organisasi; namun tidak ada pengaruh langsung kepemimpinan transformasional, budaya organisasi, dan orientasi strategis terhadap kinerja organisasi. Hasil penelitian juga menunjukkan bahwa knowledge management adalah variabel mediasi penuh budaya organisasi dan orientasi strategis terhadap kinerja organisasi, namun tidak pada hubungan antara kepemimpinan transformasional dan kinerja organisasi. Namun, untuk memberikan hasil yang lebih komprehensif, penelitian lebih lanjut diperlukan untuk melibatkan lebih banyak PDAM sebagai unit analisis dan determinan knowledge management lain untuk memperluas perspektif peran knowledge management.
\end{abstract}

Kata kunci: kepemimpinan transformasional, budaya organisasi, orientasi strategis, knowledge management, dan kinerja organisasi.

\section{Latar Belakang}

Konsep inti kepemimpinan transformasional adalah transformasi, atau perubahan organisasi, yakni perusahaan diminta untuk membuat perubahan mendasar (Tichy dan Devanna, 1986). Burns (1978) mendefinisikan kepemimpinan transformasional sebagai sebuah proses di mana para pemimpin dan pengikut saling memposisikan satu sama lain ke tingkat moralitas dan motivasi yang lebih tinggi sebagai cerminan terbaik dari perubahan tersebut. Menurut Bass (1985-1990), Avolio dan Bass (2002), ada empat perilaku yang membentuk dasar kepemimpinan transformasional: idealized influence, inspirational motivation, intellectual stimulation, dan individualised consideration. Idealized influence mencakup menetapkan contoh bagi pengikut untuk diikuti.

- Staf Pengajar FEB Universitas Mataram

Gaya ini bisa dilihat dari segi "perilaku dan atribut". Ini mengacu pada perilaku karismatik yang ditunjukkan oleh pemimpin transformasional yang mengekspresikan kepercayaan pada visi organisasi (Antonakis et al., 2003). Dengan inspirational motivation, para pemimpin mencoba menginspirasi pengikut mereka dengan memotivasi mereka untuk berkomitmen terhadap visi organisasi. Anggota didorong untuk fokus pada tujuan organisasi, dan memiliki kemampuan untuk memotivasi pengikut mereka dengan memberikan makna 
INOBIS: Jurnal Inovasi Bisnis dan Manajemen Indonesia

Volume 1, Nomor 3, Juni 2018

\section{Hermanto}

dan tantangan pada pekerjaan mereka (Avolio dan Bass, 2002, Sashkin, 2004). Intelectual stimulation adalah sejauh mana para pemimpin mendorong pengikut mereka untuk mencoba pendekatan baru, dan nenguji kembali apakah asumsi yang digunakan masih sesuai atau tidak. Mereka mendorong imajinasi, dan mengembangkan cara-cara inovatif untuk menangani masalah organisasi (DuBrin, 2012). Saat menerapkan individual consideration, pemimpin akan membangun hubungan interaktif dengan pengikut dan memberikan perhatian khusus terhadap kebutuhan mereka (Avolio dan Bass, 2002, Saenz, 2011). Keempat pola perilaku ini secara positif mempengaruhi pengikut dalam mengangkat motivasi untuk mencapai prestasi terbaik dan pengembangan diri.

Budaya organisasi (organizational culture) didefinisikan sebagai seperangkat asumsi bersama, jaminan tersirat yang dimiliki oleh kelompok dan menentukan bagaimana persepsi, pemikiran, dan reaksi pada berbagai lingkungan (Schein, 2004). OC dapat menjadi sumber keunggulan kompetitif yang berkelanjutan jika budaya itu berharga (valuable), jarang (rare), dan tidak dapat ditiru dengan sempurna (imperpectly imitable) (Barney, 1986). Budaya organisasi mewakili karakter sebuah organisasi, sebagai petunjuk hubungan kerja sehari-hari karyawannya dan membimbing mereka tentang bagaimana berperilaku dan berkomunikasi dalam organisasi, serta membimbing bagaimana hirarki perusahaan dibangun (Ribiere dan Sitar, 2003 ). Denison (1990) mengembangkan model budaya organisasi dan efektivitas berdasarkan empat sifat: keterlibatan (involvement), konsistensi (consistency), kemampuan beradaptasi (adaptability) dan misi (mission). Menurut Denison, efektivitas perusahaan terkait langsung dengan budaya organisasi (Denison, 1990).

Strategi bisnis telah dicirikan sebagai cara di mana perusahaan memutuskan untuk bersaing (Walker dan Ruekert, 1987), yang mencakup pencapaian dan pemeliharaan keunggulan kompetitif dalam industri (Varadarajan dan Clark, 1994). Teori normatif dalam strategi cenderung mengadopsi perspektif proses, konten, atau konteks (Ketchen et al., 1996). Secara teori orientasi strategis dapat dilihat dari tiga sudut pandang: pendekatan naratif (narrative approach) berusaha untuk menggambarkan secara verbal strategi holistik dari strategi yang unik untuk kejadian, situasi, dan organisasi (Czarniawska, 1998); pendekatan classificatory mencoba mengklasifikasikan strategi perusahaan sesuai dengan argumen konseptual ex ante atau hasil empiris yang telah divapai (ex pot); dan pendekatan komparatif (Morgan, 2003) mempertimbangkan strategi pada penekanan relatif yang dibuat oleh perusahaan di setiap dimensi orientasi strategis. Orientasi strategis konseptuan dari Venkatraman (1989) akan digunakan sebagai dasar konseptualisasi berikut.

Knowledge management didefinisikan sebagai proses proaktif dan sistematis dimana nilai dihasilkan dari aset berbasis intelektual atau pengetahuan dan disebarluaskan kepada pemangku kepentingan. Swan, J., Scarborough, H., dan Preston, J. (1999) mendefinisikan KM sebagai, "... ada proses atau praktik untuk menciptakan, memperoleh, menangkap, berbagi dan menggunakan pengetahuan, di manapun ia berada, untuk meningkatkan pembelajaran dan kinerja di organisasi. Nonaka \& Takeuchi (1995) mengidentifikasi empat kemungkinan mode: sosialisasi (socialization), eksternalisasi (externalization), kombinasi (combination), dan internalisasi (internalization) atau biasa disingkat SECI. Sosialisasi mengubah tacit knowledge (pengetahuan tersembunyi) menjadi tacit knowledge baru melalui interaksi sosial di antara anggota organisasi. Eksternalisasi mengubah tacit knowledge menjadi pengetahuan eksplisit (explicit knowledge). Kombinasi adalah proses penciptaan pengetahuan organisasi dimana explicit knowledge individu diubah menjadi explicit knowledge organisasi. Internalisasi adalah konversi explicit knowledge ke dalam tacit knowledge organisasi. Untuk menguji proses penciptaan pengetahuan (knowledge creation 
INOBIS: Jurnal Inovasi Bisnis dan Manajemen Indonesia

Volume 1, Nomor 3, Juni 2018

\section{Hermanto}

proceeses), penelitian ini mengadopsi model SECI oleh Nonaka (1994) karena dua alasan. Pertama, model SECI tidak hanya berisi transfer pengetahuan (knowledge transfer) tapi juga penciptaan pengetahuan (knowledge creation). Transfer pengetahuan yang ada dan penciptaan pengetahuan baru sangat signifikan dalam knowledge management. Kedua, model SECI telah banyak digunakan di banyak area penelitian seperti pembelajaran organisasi (organizational learning) dan pengembangan produk baru (Lee dan Choi, 2003).

Kinerja organisasi adalah fenomena multi dimensi yang kompleks yang sulit dipahami dan diukur (Goodman dan Pennings, 1977). Organisasi yang berbeda memiliki tujuan kinerja dan kinerja yang berbeda dapat bervariasi sesuai dengan target yang ditetapkan, periode waktu yang diamati, kriteria yang digunakan dan perspektif yang sedang diambil (misalnya pelanggan, manajer, karyawan atau pemegang saham). Pengukuran kinerja adalah isu yang kompleks dan beberapa peneliti telah berusaha untuk mengembangkan pemahaman tentang isu-isu yang relevan dengan kinerja organisasi dan pengukurannya (Kaplan dan Norton, 1996; Neely, et al., 1997). Pengukuran kinerja diperlukan dalam organisasi untuk mengevaluasi seberapa baik fungsi perusahaan. Perspektif yang diambil di sini adalah bahwa serangkaian tindakan diperlukan yang akan mencerminkan secara obyektif dan konsisten kualitas keputusan strategis yang telah dibuat di dalam perusahaan (Chakravarthy, 1986). Dengan demikian penelitian mengadopsi kinerja organisasi berdasarkan kriteria BPPSPAM untuk mengukur kinerja perusahaan dalam empat aspek yang berkaitan dengan pengukuran keuangan, layanan yang disampaikan, operasional, dan sumber daya manusia.

\section{Kajian Literatur dan Pengembangan Hipotesis}

Beberapa peneliti menjawab hubungan antara manajemen informasi dan kepemimpinan, dan bahkan lebih sedikit tentang hubungan antara kepemimpinan transformasional dan knowledge management. Pemimpin memainkan peran penting dalam membangun dan memelihara pengetahuan organisasi (organizational knowledge). Mengelola pengetahuan memerlukan upaya sadar dari para pemimpin di semua tingkat organisasi untuk mengelola tiga proses pengetahuan utama: menciptakan (creating), berbagi (sharing) dan mengeksploitasi (exploiting) pengetahuan. Teori kepemimpinan transformasional memberikan dasar untuk memahami bagaimana pemimpin mempengaruhi pengembangan pengetahuan (Conger \& Kanungo, 1998). Beberapa ahli berpendapat bahwa proses pengetahuan dalam organisasi yang efektif sangat penting untuk mencapai dan mempertahankan keunggulan kompetitif (Teece, 1998). Berdasarkan karakteristik konversi pengetahuan, Bryant (2003) mengemukakan bahwa kepemimpinan transformasional mempengaruhi bagaimana individu mendekati, menafsirkan, dan membangun konversi pengetahuan di tempat kerja. Kenyataannya, karakteristik kepemimpinan transformasional memfasilitasi proses konversi pengetahuan yang efektif (Bryant, 2003). Berdasarkan studi ini dan penelitian lainnya, hipotesis bahwa knowledge management berkontribusi positif terhadap kinerja organisasi. Politis (2001) menemukan bahwa gaya kepemimpinan selfmanagement, transformasional, dan transaksional berkaitan dengan dimensi perolehan pengetahuan. Bryant (2003) berpendapat bahwa ada hubungan yang jelas antara kepemimpinan transformasional dan knowledge management dalam organisasi.

\section{H1: Kepemimpinan transformasional berpengaruh positif terhadap knowledge management}


INOBIS: Jurnal Inovasi Bisnis dan Manajemen Indonesia

Volume 1, Nomor 3, Juni 2018

\section{Hermanto}

Budaya organisasi adalah aset tak berwujud dari suatu perusahaan. Budaya organisasi adalah tentang kepercayaan, nilai, norma, dan sikap yang mengatur bagaimana anggota organisasi berperilaku dalam kehidupan sehari-hari dalam sebuah organisasi. Tseng (2011) mengeksplorasi dampak budaya hierarkis terhadap efektivitas proses knowledge management. Wang et al. (2011) menemukan bahwa budaya organisasi terdiri dari iklim perusahaan yang secara informal dan diam-diam mendefinisikan bagaimana perusahaan mengembangkan dan menggunakan pengetahuan, sehingga memiliki pengaruh signifikan terhadap kemampuan penciptaan pengetahuan. Peneliti lain menemukan bahwa budaya organisasi atau budaya perusahaan memiliki efek positif pada knowledge management (DeLong \& Fahey, 2000; Alavi \& Leidner, 2005), serta dampak pada kesediaan individu untuk berbagi pengetahuan dalam organisasi. Nonaka \& Takeuchi (1995) menekankan pentingnya budaya organisasi untuk bertukar dan mengkomunikasikan tacit knowledge. Berdasarkan tinjauan literatur tersebut, kita dapat menyusun hipotesis tersebut.

\section{H2: Budaya organisasi berpengaruh positif terhadap knowledge management}

Pengembangan strategi melibatkan kegiatan berbasis pengetahuan secara luas dan intensif oleh karena pengetahuan sangat spesifik dan personal, maka pengetahuan yang tercipta sulit diubah menjadi memori kolektif organisasi dan penggunaan praktis (Grant, 1996; Szulanski, 1996). Proses penciptaan pengetahuan seperti sosialisasi, eksternalisasi, kombinasi, dan internalisasi menggambarkan interaksi antara pengetahuan eksplisit dan tacit (Nonaka, 1994; Nonaka dan Konno, 1998). Model penciptaan pengetahuan SECI memungkinkan perusahaan untuk bertukar dan mentransformasikan pengetahuan secara terus menerus dan dinamis melalui serangkaian proses transendental diri (Nonaka dan Konno, 1998; Nonaka et al., 2000a). Ketika mengembangkan dan menerapkan strategi usaha baru, dinamika spiral penciptaan pengetahuan memainkan peran penting dalam memfasilitasi konseptualisasi dan aktualisasi strategi.

\section{H3: Strategy berpengaruh positif terhadap knowledge management}

Pengetahuan dikenal sebagai sumber strategis (Grant, 1996). Kemampuan untuk menciptakan dan menggunakan pengetahuan memungkinkan perusahaan mengembangkan keunggulan kompetitif yang berkelanjutan karena sifatnya yang langka, sulit untuk ditiru karakteristik pengetahuan. Penelitian sebelumnya telah menyarankan peran penting penciptaan pengetahuan agar organisasi bisa mencapai keberhasilan (Kogut dan Zander, 2003; Nonaka dan Takeuchi, 1995; Gold et al., 2001). Organisasi dengan proses penciptaan pengetahuan yang lebih baik dapat menghubungkan pengetahuan dengan cara baru dan khas dan memberikan nilai bagi pelanggan (Nonaka dan Konno, 1998; Lee dan Choi, 2003). Knowledge management mencakup usaha manajerial dalam memfasilitasi akuisisi, pembuatan, penyimpanan, diseminasi, pengembangan dan penggunaan aktivitas individu atau kelompok dalam organisasi (Demarest, 1997; Rowley, 2001; Soliman \& Spooner, 2000; Bergeron, 2003). Peneliti lain juga menemukan bahwa tingkat persaingan industri yang meningkat akan mempengaruhi perusahaan yang kompetitif melalui pengembangan faktor kunci keberhasilan knowledge management (Ling et al., 2008; Darr et al., 1995).

\section{H4: Knowledge management berpengaruh positif terhadap kinerja organisasi}


INOBIS: Jurnal Inovasi Bisnis dan Manajemen Indonesia

Volume 1, Nomor 3, Juni 2018

\section{Hermanto}

Budaya organisasi mengacu pada asumsi, nilai, dan norma bersama (Schein, 1985) dan sumber keunggulan kompetitif yang berkelanjutan (Barney, 1991). Penelitian empiris menunjukkan bahwa budaya organisasi adalah faktor kunci untuk efektivitas organisasi (Lok \& Crawford, 1999; Denison, 1990; Gordon dan Di Tomaso, 1992; Peters and Waterman, 1982). Secara khusus, Lok \& Crawford (1999) menggunakan dimensi budaya organisasi Wallace (birokratis, inovatif, dan suportif) untuk menunjukkan dampaknya pada komitmen pekerja. Denison dan rekan-rekannya (Denison dan Mishra, 1995; Denison dan Neale, 1996; Fey dan Denison, 2003) mengidentifikasi dan memvalidasi empat dimensi budaya organisasi yang kondusif bagi efektivitas organisasi: kemampuan beradaptasi (adaptability), konsistensi (consistency), keterlibatan (involvement), dan misi (mission). Kemampuan beradaptasi mengacu pada sejauh mana organisasi memiliki kemampuan untuk mengubah perilaku, struktur, dan sistem agar dapat bertahan setelah perubahan lingkungan. Konsistensi mengacu pada sejauh mana keyakinan, nilai, dan harapan dipegang secara konsisten oleh anggota. Keterlibatan mengacu pada tingkat partisipasi anggota organisasi dalam pengambilan keputusan. Misi mengacu pada adanya definisi bersama tentang tujuan organisasi.

\section{H5: Budaya organisasi berpengaruh positif terhadap kinerja organisasi}

Menurut Gatignon dan Xuereb (1997), orientasi strategis adalah prinsip yang mengarahkan aktivitas dan perilaku organisasi yang penting bagi kinerja perusahaan. Konsep ini mewakili mekanisme adaptasi organisasi yang berbeda. Hubungan antara orientasi strategis dan kinerja telah menjadi topik penting dalam studi manajemen dan telah menarik perhatian para ilmuwan selama beberapa dekade (Acquaah, 2007; Venkatraman, 1989). Namun, masih ada konsensus mengenai konseptualisasi dan pengukuran orientasi strategis. Akibatnya, perspektif teoritis yang saling bertentangan digunakan serta penerapan metodologi yang kontras ditemukan (Morgan \& Strong, 2003). Hakala (2010) menggambarkannya sebagai model cara menjalankan aktivitas bisnis untuk mempertahankan dan meningkatkan kinerja organisasi. Orientasi strategis perusahaan dapat dianggap sebagai elemen kunci dengan implikasi penting bagi pengelolaan dan efisiensi UKM (Salju dan Hrebiniak 1980). Bergantung pada orientasi strategis yang diadopsi, perusahaan dapat menekankan aspek yang lebih banyak atau kurang seperti posisi teknologi, inovasi, desain organisasi, dan manajemen personalia (Conant, Mokwa, dan Varadarajan 1990). Aspek manajemen ini dapat menentukan kinerja perusahaan dan efisiensi bisnis. (Slater dan Narver 1993)

\section{H6: Strategy berpengaruh signifikan terhadap kinerja organisasi.}

Pemimpin transformasional ingin mencapai hasil di luar apa yang normal dan menetapkan misi tim yang lebih tinggi, merangsang karyawan untuk berpikir secara inovatif mengenai masalah atau tugas, dan menempatkan tujuan kelompok atas kepentingan pribadi (James, 2005). Perilaku pemimpin transformasi berpengaruh dalam memotivasi karyawan, untuk membuat mereka lebih sadar akan hasil tugas, merangsang kebutuhan pengembangan diri untuk mencapai tingkatan kinerja organisasi. Dalam studinya tentang praktik kepemimpinan transformasional di perusahaan-perusahaan Rusia Elenkov (2002) meneliti dampak sebelumnya terhadap kinerja organisasi. Menggunakan Kuesioner Kepemimpinan Multifaktor, Elenkov (2002) menganalisis perilaku kepemimpinan 253 pemimpin. Hasil analisi menunjukkan korelasi kuat antara praktik kepemimpinan transformasional dan kinerja 
INOBIS: Jurnal Inovasi Bisnis dan Manajemen Indonesia

Volume 1, Nomor 3, Juni 2018

\section{Hermanto}

organisasi. Dalam kajian mengenai hubungan antara gaya kepemimpinan transformasional dan kinerja organisasi, (Zhu et al., 2005) mengidentifikasi 170 perusahaan dari Singapura, hubungan positif antara kepemimpinan transformasional dan kinerja organisasi. Hasil penelitian juga menunjukkan bahwa manajemen sumber daya manusia yang efektif memperkuat hubungan antara kepemimpinan dan kinerja melalui peningkatan komitmen, dan motivasi intelektual yang lebih tinggi.

\section{H7: Kepemimpinan transformasional berpengaruh positif terhadap kinerja organisasi.}

Pemimpin transformasional memiliki karisma, memberikan inspirasi dan mendorong rangsangan intelektual (Bass, 1999; Bass dan Avolio, 2000; Conger, 1999). Karisma menghasilkan kebanggaan, keyakinan dan rasa hormat bahwa para pemimpin bekerja untuk mendorong karyawan bangga memiliki pemimpin dan organisasinya. Pemimpin transformasional memberikan inspirasi dengan memotivasi pengikut, terutama melalui komunikasi yang memberikan harapan. Pemimpin seperti itu juga mempromosikan rangsangan intelektual dengan meningkatkan pengetahuan karyawan sehingga para karyawan dapat menjadi inovatif dalam pendekatan terhadap pemecahan masalah dan solusi. Berbagai penelitian menganalisis pengaruh kepemimpinan transformasional terhadap kinerja organisasi melalui konstruk antara seperti budaya (misalnya, Ogbonna dan Harris, 2000), kewirausahaan (misalnya, García Morales et al., 2006), knowledge management (misalnya, Gowen et al. 2009), human capital yang mampu meningkatkan kualitas manajemen sumber daya manusia (Zhu et al., 2005), strategi persaingan (misalnya, Menguc et al., 2007), dan kapasitas absortif (misalnya Morales et al., 2008a, b). Namun, pemahaman tentang proses dimana pemimpin memberikan pengaruh ini masih terbatas dan sangat spekulatif (Bass, 1999; Conger, 1999). Investigasi ini bertujuan untuk menganalisis secara empiris apakah kepemimpinan transformasional memberikan pengaruh ini pada kinerja organisasi melalui mediasi knowledge management (SECI).

\section{H8: Knowledge management memediasi sepenuhnya pengaruh kepemimpinan transformasional terhadap kinerja organisasi.}

Penelitian sebelumnya menunjukkan bahwa budaya sebagai faktor kunci bagi kinerja organisasi (Deal and Kennedy, 1982; Denison, 1990; Gordon dan Di Tomaso, 1992 Peters and Waterman, 1982). Secara khusus, Denison dan rekan-rekannya (Denison, 1990; Denison dan Mishra, 1995; Denison dan Neale, 1996; Fey and Denison, 2003) mengidentifikasi dan memvalidasi empat dimensi budaya organisasi yang kondusif bagi kinerja organisasi: kemampuan beradaptasi (adaptability), konsistensi (consistency), keterlibatan (involvement), dan misi (mission). Studi lain menyiratkan hubungan positif antara budaya organisasi Denison dan model SECI Nonaka \& Takeuchi seperti (Andreeva \& Ikhilchik, 2014; Kaur et al., 2012; Gray \& Densten, 2013; Li et al., 2012). Budaya organisasi tidak secara langsung memberi pengaruh pada kinerja organisasi; Sebaliknya, ia memberikan pengaruhnya melalui pembentukan perilaku anggota organisasi. Dalam dunia yang penuh dengan ketidakpastian, bagian terpenting dari pengambilan keputusan adalah mencerna informasi dari lingkungan ke struktur yang tidak diketahui.

H9: Knowledge management memediasi sepenuhnya pengaruh budaya organisasi terhadap kinerja organisasi 
INOBIS: Jurnal Inovasi Bisnis dan Manajemen Indonesia

Volume 1, Nomor 3, Juni 2018

\section{Hermanto}

Beberapa kajian sebelumnya menunjukkan adanya hubungan positif antara strategi organisasi dan knowledge management. Misalnya, Pedler dkk. (1991) menyoroti pentingnya pendekatan analitis terhadap strategi yang berkontribusi terhadap pembelajaran. Senge (1990) menekankan kemampuan untuk membayangkan masa depan yang sangat penting bagi organisasi pembelajaran. Watkins dan Marsick (1996) menekankan pendekatan proaktif terhadap pembelajaran baru dan pasar baru dalam membangun organisasi pembelajaran (Watkins dan Marsick, 1996). Pandangan berbasis pengetahuan menganggap perusahaan sebagai seperangkat aset pengetahuan dan peran perusahaan dalam menciptakan dan menggunakan aset-aset ini untuk menciptakan nilai (Grant, 1996). Strategi organisasi kemudian dapat dianggap sebagai rencana organisasi untuk menciptakan dan menerapkan berbagai aset pengetahuan. Knowledge management secara parsial mempengaruhi strategi melalui pemahaman konsep pengetahuan strategis, mengkoordinasikan transfer pengetahuan penting, dan mengarahkan upaya eksploitasi pengetahuan utama yang dapat menghasilkan peningkatan efektivitas. Terlepas dari jalur pengelolaan pengetahuan, strategi memengaruhi kinerja organisasi melalui saluran lain seperti sistem kontrol dan skema alokasi sumber daya.

\section{H10: Knowledge management memediasi sepenuhnya pengaruh strategy terhadap kinerja organisasi.}

\section{Metodologi Penelitian}

Pada penelitian ini digunakan pendekatan paradigma positivis yang menekankan pada pengujian teoritis dimana data dikumpulkan dengan menggunakan survei kuesioner dan wawancara mendalam untuk mendapatkan hasil yang valid dan dapat diandalkan (Cooper \& Schindler, 2011). Ada 8 PDAM di Provinsi Nusa Tenggara Barat sebagai sampel survei (sampel jenuh). 70 responden, terdiri dari 18 manajer tingkat atas dan 52 manajer tingkat menengah, dipilih berdasarkan purposive sampling berdasarkan kriteria telah menduduki jabatan tersebut sekurang-kurangnya 3 tahun. Identifikasi dan pemilihan sampel responden dipertimbangkan dengan memperhatikan pemahaman terhadap proses knowledge management di dalam perusahaan. Sehingga untuk membatasi kesalahan pengukuran, ditetapkan bahwa sekurang-kurangnya Kepala Bagian Keuangan dan Tehnik atau yang sederajat dapat diterima sebagai responden karena pemahaman mereka terhadap proses pengambilan keputusan.

Item survei diadaptasi dari instrumen yang digunakan dalam penelitian sebelumnya dan setiap jawaban perseptif responden didasarkan pada lima skala Likert. Untuk mengukur persepsi subyek tentang kepemimpinan transformasional, Kuesioner Kepemimpinan Multifaktor (MLQ-5x / Short Form) (Bass \& Avolio, 1995) digunakan. Untuk tujuan penelitian ini, empat subskala dimasukkan bersama-sama dan digunakan sebagai ukuran kepemimpinan transformasional (Karisma, Inspirasi, Perhatian Individu, dan Stimulasi Intelektual).

Untuk menilai budaya organisasi diadopsi dari Denison dan rekan-rekannya (Denison, 1990; Denison dan Mishra, 1995; Denison dan Neale, 1996; Fey dan Denison, 2003) yang mencakup empat dimensi fungsional: kemampuan beradaptasi, konsistensi, keterlibatan, dan misi. Skala mengukur sampai sejauh mana sebuah organisasi dianggap menampilkan empat dimensi karakteristik, misalnya, sampai sejauh mana "kita memiliki visi bersama mengenai bagaimana organisasi nantinya di masa depan. Aspek strategy menggunakan pendekatan Venkatraman (1989), disebut STROBE (Strategic Orientasi of Business Enterprise). Alasan 


\section{Hermanto}

mengapa hal itu digunakan sebagai pengganti tipologi strategis karena STROBE menggambarkan intensitas karakteristik strategi dari pada dilihat sebagai kategori. STROBE mengukur sampai sejauh mana responden memandang strategi organisasi melalui tiga karakteristik yakni analysis, futurity dan riskiness. Untuk mengukur proses penciptaan pengetahuan berdasarkan empat mode teori konversi pengetahuan, kuesioner dikembangkan berdasarkan penelitian sebelumnya (Tseng, 2010) dan secara empiris menguji konsistensi internal item dan validitas konstruk untuk memastikan masalah validitas umum instrumen. Untuk mengukur tingkat kinerja organisasi yang dirasakan berdasarkan pengukuran BPPSPAM terdiri dari 4 dimensi yaitu dimensi keuangan, jasa, operasional, dan sumber daya manusia dimana masing-masing bagian memiliki lima item pengukuran.

Merujuk pada Hwang \& Takane (2004), Generalised Structure Component Analysis (GSCA) digunakan untuk menilai model pengukuran konfirmatori. Seperti namanya, GSCA terletak pada tradisi analisis komponen. Ini menggantikan komponen untuk faktor seperti pada PLS. Selain itu, GSCA juga menawarkan kriteria optimasi kuadrat terkecil global, yang secara konsisten diminimalkan untuk mendapatkan estimasi parameter model. Dengan demikian, GSCA dilengkapi dengan ukuran keseluruhan kesesuaian model sementara sepenuhnya mempertahankan semua kelebihan PLS (misalnya, asumsi distribusi yang tidak dibatasi, tidak ada solusi yang tidak benar, dan estimasi skor komponen unik). Selain itu, GSCA menangani analisis jalur yang lebih beragam, dibandingkan dengan PLS. Misalnya, dengan mudah dapat memasukkan model jalur yang sama ke lebih dari satu kelompok dengan pemaksaan batasan kelompok secara opsional, yang tidak dapat diakomodasi oleh PLS (Hwang \& Takane, 2004).

\section{Analisis Deskriptif}

Analisis GSCA menerapkan pengukuran goodness fit berdasarkan skor FIT, AFIT (adjusted FIT), GFI (goodness of fit index), dan SRMR (Standard Root Mean Square). Tabel 1 di bawah ini menunjukkan goodness of fit model struktural dan keseluruhan goodness of fit.

Table1. Goodness of FIT Model Structural

\begin{tabular}{|c|c|c|}
\hline \multicolumn{2}{|c|}{ Model Fit } & Reference Score \\
\hline FIT & $\mathbf{0 . 5 9 5}$ & $\mathbf{0}-\mathbf{1}$ \\
\hline AFIT & $\mathbf{0 . 5 9 8}$ & $\mathbf{0}-\mathbf{1}$ \\
\hline GFI & $\mathbf{0 . 9 7 8}$ & cut-off $\geq 0.90$ \\
\hline SRMR & $\mathbf{0 . 1 5 8}$ & cut-off $\leq 0.08$ \\
\hline NPAR & $\mathbf{4 5}$ & - \\
\hline
\end{tabular}

Tabel di atas menunjukkan bahwa semua model fit lebih dari nilai referensi minimum. Skor Fit sebesar 0,595 berarti bahwa 59\% varians data dapat dijelaskan oleh model. Skor bisa turun antara 0 sampai 1 berarti bahwa jika skor mendekati berarti model yang lebih baik menjelaskan variansnya. Sementara GFI (goodness fit index) mengungkapkan nilai di atas cut-off value.

Pengukuran ini terdiri dari validitas konvergen yang menggambarkan korelasi antara indikator dan skor variabel laten dan skor loading factor yang diperoleh harus antara 0,5 sampai 0,6.. Validitas diskriminan (AVE) direkomendasikan $>0.5$ dan reliabilitas konsistensi internal (alpha) yang diukur dengan reliabilitas komposit yang menggambarkan 
INOBIS: Jurnal Inovasi Bisnis dan Manajemen Indonesia

Volume 1, Nomor 3, Juni 2018

\section{Hermanto}

hubungan antara variabel laten dan indikator blok, nilainya lebih dari 0,60 lebih baik. Skor validitas konvergen secara keseluruhan lebih besar 0,6 berarti bahwa semua indikator sesuai untuk menggambarkan variabel laten terkaitnya. Validitas konvergen terendah berdasarkan analisis GSCA diperoleh indikator stimulasi intelektual dari variabel kepemimpinan transformasional $(0,670)$, dan skor tertinggi dengan indikator aspek operasional variabel dari kinerja organisasi $(0,889)$.

Nilai validitas diskriminan dan reliablitas komposit ditunjukkan pada table berikut.

Table 2. Value of AVE and Alpha

\begin{tabular}{|l|c|c|}
\hline \multicolumn{1}{|c|}{ Variable AVE } & Alpha \\
\hline $\begin{array}{l}\text { Transformational Leadership } \\
\text { (X1) }\end{array}$ & 0.504 & 0.669 \\
\hline Organizational Culture (X2) & 0.550 & 0.722 \\
\hline Strategic Orientation (X3) & 0.551 & 0.591 \\
\hline Knowledge Management (Y1) & 0.613 & 0.783 \\
\hline $\begin{array}{l}\text { Organizational Performance } \\
\text { (Y2) }\end{array}$ & 0.643 & 0.812 \\
\hline
\end{tabular}

Uji hipotesis dan koefisien jalur dampak langsung akan dilakukan pada lima variabel laten dimana terdapat 7 hubungan langsung antara variabel eksogen dan variabel endogen. Hasilnya ditunjukkan oleh nilai koefisien jalur dan nilai kritis pada nilai signifikan alpha $=$ 0,05 .

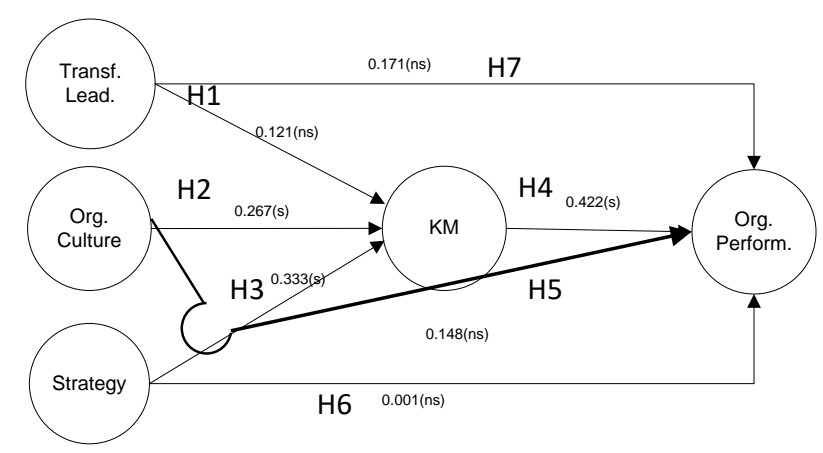

\section{Gambar : Diagram Koefisien jalur dan Uji hipotesis}

Berdasarkan nilai pada diagram di atas, dapat dibuat tabel seluruh nilai berikut. 
INOBIS: Jurnal Inovasi Bisnis dan Manajemen Indonesia

Volume 1, Nomor 3, Juni 2018

Hermanto

Tabel 3. Koefisien jalur hubungan langsung dan Uji hipotesis

\begin{tabular}{|c|l|c|c|c|c|}
\hline Hipotesis & \multicolumn{1}{|c|}{ Relationship } & $\begin{array}{c}\text { Path } \\
\text { Coeff. }\end{array}$ & CR & \multicolumn{2}{|c|}{ Meaning } \\
\hline H1 & TL $(\mathrm{X} 1) \rightarrow \mathrm{KM}(\mathrm{Y} 1)$ & 0.121 & 0.133 & NS & Rejected \\
\hline H2 & OC $(\mathrm{X} 2) \rightarrow \mathrm{KM}(\mathrm{Y} 1)$ & 0.267 & $2.1^{*}$ & significant & accepted \\
\hline H3 & $\begin{array}{l}\text { Strategy }(\mathrm{X} 3) \rightarrow \mathrm{KM} \\
(\mathrm{Y} 1)\end{array}$ & 0.333 & $3.15^{*}$ & significant & accepted \\
\hline H4 & KM $(\mathrm{Y} 1) \rightarrow$ OP $(\mathrm{Y} 2)$ & 0.422 & $2.9^{*}$ & significant & accepted \\
\hline H5 & OC $(\mathrm{X} 2) \rightarrow$ OP (Y2) & 0.148 & 1.04 & NS & Rejected \\
\hline H6 & $\begin{array}{l}\text { Strategy }(\mathrm{X} 3) \rightarrow \text { OP } \\
(\mathrm{Y} 2)\end{array}$ & 0.001 & 0.01 & NS & Rejected \\
\hline H7 & TL $(\mathrm{X} 1) \rightarrow$ OP $(\mathrm{Y} 2)$ & 0.171 & 0.118 & NS & Rejected \\
\hline
\end{tabular}

Hipotesis 2 dan 3 memprediksi bahwa budaya organisasi dan strategi secara signifikan berpengaruh terhadap knowledge management serta hubungan antara knowledge management dan kinerja organisasi (hipotesis 4). Di sisi lain, hipotesis 1 kepemimpinan transformasional) tidak berpengaruh secara signifikan dengan knowledge management dan organisasi. kinerja. Ada juga yang menemukan bahwa hipotesis 5, 6, dan 7 semuanya tidak berpengaruh secara signifikan dengan kinerja organisasi, dilihat dari hasil korelasi bevariate (seperti ditunjukkan pada Tabel 3). Knowledge management $(\mathrm{CR}=2,9, \mathrm{p}>0,05)$ menunjukkan hubungan positif dan signifikan dengan kinerja organisasi. Budaya organisasi $(\mathrm{CR}=1,04, \mathrm{p}>0,05)$, dan strategi $(\mathrm{CR}=0,01, \mathrm{p}>0,05)$ juga menunjukkan hubungan positif dengan efektivitas organisasi namun tidak signifikan. Kedua variabel budaya organisasi (CR $=2.1, \mathrm{p}>0,05)$ dan strategi $(\mathrm{CR}=3,15, \mathrm{p}>0,05)$ menunjukkan hubungan positif dan signifikan terhadap knowledge management, namun tidak untuk kepemimpinan transformasional. Berdasarkan tabel di atas, tiga hipotesis $(\mathrm{H} 2, \mathrm{H} 3$, dan $\mathrm{H} 4)$ diterima dan sisanya ditolak.

Koefisien jalur ini menunjukkan adanya pengaruh tidak langsung variabel independen (kepemimpinan transformasional, budaya organisasi, dan strategi) terhadap variabel terikat (organizational performance) yang dimediasi oleh knowledge management (model SECI). Berdasarkan proses statistik ini, dapat disimpulkan apakah SECI Model memediasi hubungan sepenuhnya (complete mediated) atau tidak.

Table 4. Path Coefficient of Mediating Impact

\begin{tabular}{|c|c|c|c|c|c|c|c|}
\hline \multirow{2}{*}{ No } & \multirow{2}{*}{ Relationship } & \multirow{2}{*}{$\begin{array}{l}\text { Mediating } \\
\text { variable }\end{array}$} & \multicolumn{4}{|c|}{ Path Coefficient } & \multirow{2}{*}{ Meaning } \\
\hline & & & $\mathrm{c}$ & $\mathrm{d}$ & $\mathrm{a}$ & $\mathrm{b}$ & \\
\hline 1 & $\mathrm{OC}(\mathrm{X} 2) \rightarrow \mathrm{OP}(\mathrm{Y} 2)$ & KM & $0.267 *$ & $0.422 *$ & $0.148^{\mathrm{ns}}$ & - & $\begin{array}{l}\text { Complete } \\
\text { Mediation }\end{array}$ \\
\hline 2 & $\begin{array}{l}\text { Strategy }(\mathrm{X} 3) \rightarrow \mathrm{OP} \\
(\mathrm{Y} 2)\end{array}$ & KM & $0.333^{*}$ & $0.422 *$ & $0.001^{\mathrm{ns}}$ & - & $\begin{array}{l}\text { Complete } \\
\text { Mediation }\end{array}$ \\
\hline 3 & $\mathrm{TL}(\mathrm{X} 1) \rightarrow \mathrm{OP}(\mathrm{Y} 2)$ & KM & $0.121^{\mathrm{ns}}$ & $0.422 *$ & $0.171^{\mathrm{ns}}$ & - & $\begin{array}{c}\text { Not } \\
\text { mediated }\end{array}$ \\
\hline
\end{tabular}


INOBIS: Jurnal Inovasi Bisnis dan Manajemen Indonesia

Volume 1, Nomor 3, Juni 2018

\section{Hermanto}

Hipotesis 8, 9 dan 10 memprediksi bahwa knowledge management sepenuhnya memediasi hubungan antara kepemimpinan transformasional, budaya organisasi, dan strategi organisasi dengan kinerja organisasi. Temuan tersebut mendukung hipotesis 9 dan 10. Kedua budaya dan strategi organisasi memiliki pengaruh positif dan signifikan terhadap knowledge management (nilai CR masing-masing adalah 0,267 dan 0,333), dan pengaruh positif knowledge management terhadap kinerja organisasi $(\mathrm{CR}=0,422)$. Selanjutnya, hasilnya juga menunjukkan efek langsung dari knowledge mangement terhadap kinerja organisasi $(\mathrm{CR}=$ $0,422, \mathrm{p}<0.01$ ). Selain efek ini, penelitian ini menunjukkan efek tidak langsung dari budaya organisasi \& strategi terhadap kinerja organisasi. Berdasarkan temuan ini, dapat disimpulkan bahwa knowledge management sepenuhnya memediasi hubungan antara budaya organisasi dan strategi terhadap kinerja organisasi walaupun hubungan langsung kedua variabel tersebut terhadap kinerja organisasi tidak signifikan. Di sisi lain, penelitian ini menunjukkan bahwa knowledge management tidak memediasi hubungan tidak langsung antara kepemimpinan transformasional terhadap kinerja organisasi. Jadi, temuan ini tidak mendukung hipotesis 8 .

\section{Simpulan}

Penelitian sebelumnya menunjukkan bahwa seorang pemimpin memiliki peran penting dalam proses knowledge management dalam hal menyampaikan visi, bagaimana memotivasi pengikut, membangun sistem, serta menentukan struktur organisasi untuk mencapai konversi pengetahuan menjadi keunggulan kompetitif (Nonaka \& Toyama, 2005; Nonaka et al., 2006; Joshi, 2000; Yeh et al., 2006; Wong, 2005; Sin et al., 2009). Nonaka dkk. (2006), khususnya, menemukan bahwa peran pemimpin adalah untuk memfasilitasi penciptaan pengetahuan dari pada mengendalikan, atau mengarahkan. Oleh karena itu, karakteristik fleksibel seorang pemimpin diperlukan untuk meraih kesuksesan kontrol mekanistik.

Keseluruhan pola efek antara variabel eksogen dan endogen dalam model GSCA konsisten dengan hipotesis yang diajukan, namun hanya beberapa jalur yang diuji dikonfirmasi. Dari 7 jalur yang diuji di antara variabel-variabel ini, 3 adalah signifikan. Untuk variabel kepemimpinan transformasional, tidak ada pengaruh yang signifikan terhadap knowledge management (sebagai variabel mediasi) dan kinerja organisasi. Budaya organisasi dan orientasi strategis memiliki dampak positif dan signifikan terhadap knowledge management, namun bertentangan dengan kinerja organisasi. Namun, knowledge management memiliki pengaruh positif dan signifikan terhadap kinerja organisasi.

Knowledge management ditemukan sepenuhnya memediasi pengaruh budaya organisasi dan strategi terhadap kinerja organisasi. Temuan ini menunjukkan bahwa seberapa baik pengetahuan dikelola sebagian besar terkait dengan seberapa baik nilai budaya diterjemahkan menjadi nilai bagi organisasi. Selanjutnya, budaya memiliki kontribusi yang lebih besar terhadap knowledge management dibandingkan variabel kepemimpinan transformasional. Hal ini mungkin disebabkan oleh fakta bahwa budaya menentukan keyakinan dasar, nilai, dan norma mengenai mengapa dan bagaimana pengetahuan, pembagian, dan pemanfaatan pengetahuan dalam sebuah organisasi. Temuan ini memperkuat perhatian untuk menciptakan budaya organisasi yang kondusif bagi pembelajaran dan knowledge management (Davenport dan Prusak, 1998; DeLong dan Fahey, 2000). 
INOBIS: Jurnal Inovasi Bisnis dan Manajemen Indonesia

Volume 1, Nomor 3, Juni 2018

Hermanto

\section{Daftar Pustaka}

Acquaah, Moses \& Yasai-Ardekani, Masoud, 2008, Does the implementation of a combination competitive strategy yield incremental performance benefits ? A new perspective from a transition economy in Sub-Saharan Africa, Journal of Business Research, 61, 346-354.

Alavi, Maryam, Kayworth, Timothy R. \& Leidner, Dorothy E., 2005, An Empirical Examination of the Influence of Organizational Culture on Knowledge Management Practices, Journal of Management Information Systems, 22 (3), 191-224.

Barney, J. B., 1995, Looking inside for competitive advantage, Journal of Management Executive, 9(4), 49-60.

Barney, Jay B., 1986, Types of competition and the theory of strategy: toward an integrative framework, Academy of Management Review, 11 (4), 791-800.

Bass, Bernard M, 1985, Leadership: Good, Better, Best, Leadership and Performance Beyond Expectations, The Free press, 26-40.

Bergeron, Bryan, 2003, Essentials of Knowledge Management, Hoboken, New Jersey, John Wiley \& Sons, Inc.

Bryant, S. E. (2003), The Role of Transformational and Transactional Leadership in Creating, Sharing and Exploiting Organizational Knowledge, The Journal of Leadership and Organizational Studies, Vol. 9, No. 4, pp. 32-44

Chakravarthy B.S., Measuring strategic performance, Strategic Management Journal, 1986;7:437-58.

Conger, J.A., 1999, Charismatic and transformational leadership in organizations: An insider's perspective on these developing streams of research, Leadership Quarterly, 10: $145-169$.

Conant J.S., Mokwa M.P., Varadarajan P.R., Strategic types, distinctive marketing ompetencies, and organizational performance, Strategic Management Journal, 1990;11:365-83.

Cooper, R. Donald \& Schindler, S. Pamela, 2011, Business Research Methods, McGraw Hill International Edition, Eleventh Edition

Darr, Eric D., Argote, Linda, Epple, Dennis, 1995, The Acquisition, Transfer, and Depreciation of Knowledge in Service Organization: Productivity in Franchises, Management Science, 41 (11), 1750-1762.

De Long, David W. \& Fahey, Liam, 2000, Diagnosing cultural barriers to knowledge management, Academy of Management Executive, 14 (4), 113-127.

Demarest, Marc, 1997, Understanding Knowledge Management, Long Range Planning, 30 (3), 374-384.

Denison, Daniel R. \& Mishra, Aneil K., 1995, Toward a theory of organizational culture and effectiveness, Organization Science, 6 (2), 204-223.

Denison \& Neale, 1996, Denison Organizational Culture Survey, Facilitator Guide, Ann Arbor, MI: Aviat.

Denison, Daniel R., 1984, Bringing corporate culture to the bottom line, Organizational Dynamics.

Elenkov, Detelin S., 2002, Effects of leadership on organizational performance in Russian companies, Journal of Business Research, 55, 467-480.

Fey, Carl F. \& Denison, Daniel R., 2003, Organizational culture and effectiveness: Can American theory be applied in Russia ?, Organization Science, 14 (6), 686-706. 
INOBIS: Jurnal Inovasi Bisnis dan Manajemen Indonesia

Volume 1, Nomor 3, Juni 2018

Hermanto

Gold, Andrew H., Malhotra, Arvind, \& Segars, Albert H., 2001, Knowledge Management: Organizational Capabilities Perspective, Journal of Management Information Systems, 18

Gordon, George G. \& DiTomaso, Nancy, 1992, Predicting corporate performance from organizational culture, Journal of Management Studies, 29 (6), 783-798.

Grant, R. M. (1996), Toward a knowledge-based theory of the firm, Strategic Management Journal, (17), Winter Special Issue, 109-22.

Gray, J. H. \& Densten, I. L., (2005), "Towards an Integrative Model of Organizational Culture and Knowledge Management", International Journal of Organizational Behavior, 2 (9), 594-

Hwang, Heungsun \& Takane, Yoshio, 2004, Generalized Structured Component Analysis, Psychometrika, vol. 69, No. 1, 81-89.

Kaplan R.S. \& Norton D.P., The balanced scorecard - measures that drive performance, Harvard Business Review, 1992;70:71-9.

Kogut, Bruce \& Zander, Udo, 1992, Knowledge of the Firm, Combinative Capabilities, and the Replication of Technology, Organization Science.

Lee, Heeseok \& Choi, Byounggu, 2003, Knowledge Management Enablers, Processes, and Organizational Performance: An Integrative View and Empirical Examination, Journal of Management Information Systems, 20 (1), 179-228.

Lin, C. H., Peng, C. H., \& Kao, D. T. (2008), The innovativeness effect of market orientation and learning orientation on business performance, International Journal of Manpower, 29(8), 752-772.

Lok, Peter \& Crawford, John, 1999, The relationship between commitment and organizational culture, subculture, leadership style and job satisfaction in organizational change and development, Leadership \& Organization Development Journal, 20 (7), 365-373.

Lok, Peter \& Crawford, John, 2003, The effect of organizational culture and leadership style on job satisfaction and organizational commitment - A cross-national comparison, Journal of Management Development, 23 (4), 321-338.

Morales, Victor Jesus Garcia, Barrionuevo, Maria Magdalena Jimenez \& Gutierrez, Leopoldo Guiterrez, 2011, Transformational leadership influence on organizational performance through organizational learning and innovation, Journal of Business Research.

Morgan Robert E., \& Strong Carolyn A., 2003, Business performance and dimensions of strategic orientation, Journal of Business Research.

Neely, Andy, Bourne, Mike \& Kennerly, Mike, 2000, Performance measurement system design: developing and testing a process-based approach, International Journal of Operations \& Production Management.

Neely, Andy, Richards H., Mills J., Platts K., \& Bourne M., Designing performance measures: a structured approach, International Journal of Operations \& Production Management, 1997; 17: 1131-1152

Nonaka, Ikujiro \& Takeuchi, Hirotaka, 1995, The Knowledge-Creating Company: How Japanese Companies Create the Dynamics of Innovation, Oxford University Press, New York.

Nonaka, Ikujiro, 1994, A Dynamic Theory of Organizational Knowledge Creation, Organization Science. 
INOBIS: Jurnal Inovasi Bisnis dan Manajemen Indonesia

Volume 1, Nomor 3, Juni 2018

\section{Hermanto}

Nonaka, Ikujiro, 2006, Creating Sustainable Competitive Advantage Through Knowledgebased Management, http://www.google.com.Download September 2011.

Nonaka, Ikujiro, Toyama, Ryoko \& Konno, Noboru, 2000, SECI, Ba and leadership: a unified model of dynamic knowledge creation, Long Range Planning, 33, 5-34.

Ogbonna, Emmanuel \& Harris, Lloyd C., 1998, Managing Organizational Culture: Compliance or Genuine Change?, British Journal of Management, Vol. 9, 273-288.

Peters, Thomas J., \& Waterman, Robert H., Jr., 1982, In Search of Excellence - Lessons from America's Best-Run Companies, HarperCollins Publisher, USA.

Politis, John D., 2001, The relationship of various leadership styles to knowledge management, Leadership \& Organizational Development Journal, 354-364.

Rowley, Jennifer, 1999, What is knowledge management ?, Library Management, 20 (8).

Saenz, J., et al., 2009. Knowledge sharing and innovation performance: A comparison between high - tech and low- tech companies, Journal of Intellectual Capital, Vol.10, No.1, pp.22 -

Schein, Edgar H., 2004, Organizational Culture and Leadership, John Wiley \& Sons, Inc., San Fransisco, CA.

Slater, Stanley F. \& Olson, Eric M., 2000, Strategy type and performance: The influence of sales force management, Strategic Management Journal, 21, 813-829.

Snow, Charles C. \& Hambrick, Donald C., 1980, Measuring organizational strategies: some theoretical and methodological problems, Academy of Management Review, 5 (4), 527538.

Soliman, Fawzy \& Spooner, Kery, 2000, Strategies for implementing knowledge management: role of human resources management, Journal of Knowledge Management, 4 (4), 337-345.

Teece, David D., Pisano, Gary, Shuen, Amy, 1997, Dynamic capabilities and strategic

Tseng, Shu-Mei, 2010, The correlation between organizational culture and knowledge conversion on corporate finance, Journal of Knowledge Management, 14 (2), 269-284.

Venkatraman N. \& Ramanujam V., Measurement of business performance in strategy research: a comparison of approaches, Academy Management Review, 1986;11:80114.

Venkatraman N., 1989, Strategic orientation of business enterprises: the construct, dimensionality, and measurement, Management Science, 35:942-62. 